\title{
THRIVING IN THE LANDSCAPE OF DOCTORAL PROGRAMS: THE CASE OF D.SC. AT XUNIVERSITY
}

\author{
Sushma Mishra, Robert Morris University, mishra@rmu.edu \\ Donna Cellante, Robert Morris University, cellante@rmu.edu \\ Fredrick Kohun, Robert Morris University, Kohun@rmu.edu
}

\begin{abstract}
This study presents a SWOT analysis of an existing Doctor in Science (DSc) program at XUniversity. An open-ended survey was administered to alumni of this program and results were analyzed for existing themes in the data. The strengths of the program were identified as the format, structure, and faculty of the program. The weaknesses were more in line with improved syllabi description and competitive cohort admission criteria. The opportunities were identified as collaboration with industry and alumni getting opportunities in teaching. Threats were along the lines of increased costs and the title of the program. Implications are presented, and conclusions drawn.
\end{abstract}

Keywords: Doctor of Science (DSc), Communications, Research, Andragogy, SWOT, Survey, Thematic analysis, Convergence

\section{INTRODUCTION}

Doctoral programs in the information systems and computer technology field share two identifiable attributes: (1) the computer field is changing rapidly, there is frequent change in program content; and (2) the information systems and computer area is evolving so rapidly, new bodies of knowledge are continually being created and there is no one fixed core body of knowledge. As a result, there are multiple variations and sub niches of programs that can be labeled as information and computer systems. Each program takes on a different "look and feel" such that no two programs are alike.

There are multiple types of doctoral programs available today that have variety of formats and modalities to reach out to students and impart doctoral level education. On one side of this spectrum is the traditional on-ground full-time $\mathrm{PhD}$ program that on average requires 8.2 years to complete (O'Shaughnessy, 2012). The other side is the completely online program with no requirement of any face-to-face meetings throughout the process. In between the two extremes, there are multiple models comprising a hybrid of structures and includes multiple modalities of delivering the content and interaction. The market space for doctoral education is competitive and has a plethora of products to pick from offered by different players such as traditional universities, colleges, for profit institutions, and not for profit institutions to international organizations. Complexity of such models multiplies when we factor in various essential parameters that are inherent to success of these programs. Some of these factors are expected number of years for graduation, cost of the program, rigor of curriculum, advising model, mentorship, and number of credits to name a few.

Doctoral programs have a high attrition rate. Half of graduate students leave school without completing their doctoral program (Patterson, 2016). There are several reasons cited for this in the research literature. Some of these reasons include (Patterson, 2016): student frustration, lack of proper guidance during the program, changing requirements, and lack of mentoring relationships with professors. It is not surprising, given more failure than success stories in $\mathrm{PhD}$ programs, that less than $1 \%$ of the population has a doctoral degree.

In this competitive space of doctoral programs, the Doctor in Science (DSc) program in Information Systems (IS) and Communications at XUniversity is evolving to keep current in the IS field and be relevant to students aspiring for a doctorate in such an applied field. This program has successfully demonstrated agility in structure and format and delivered consistently a graduation rate of about $90 \%$ every year. What are the factors that make a doctoral program 
successful? The objective of this study is to understand the fundamental drivers that allow recruiting, retaining, and graduating students in a doctoral program at such high rate and sustain in the market in the long run. In pursuit of this understanding, the case of XUNIVERSITY DSc program is used as a data point to describe the phenomenon under study.

This study critically analyzes the Doctor in Science (DSc) program at XUniversity in terms of overall effectiveness of this program. This case study sets out to understand the strengths, weaknesses, opportunities, and threats associated with the program. The guiding questions for this study are:

RQ1: What are the strengths, weaknesses, opportunities, and threats of DSc program at XUNIVERSITY?

RQ2: What are the perceptions of alumni of this program in terms of effectiveness of this degree?

The next section talks about the DSc program at XUNIVERSITY, its structure, and format. The methodology of the study follows with data collection details and analysis protocol. Findings from the data are presented followed by a discussion about the results. Implications are drawn and conclusions are presented.

\section{THE DOCTORAL PROGRAM AT XUNIVERSITY}

The Doctor of Science in Information Systems and Communications degree at XUniversity (XUNIVERSITY) started in 1999. The first group of students graduated from this program in May of 2002. The second group started in 2000 and completed their degrees in 2003 and so on to the most recent group (the $20^{\text {th }}$ ) starting in 2017 with expected completion in 2020. The goal of this "lock step" three-year program as stated in the university materials is to "address the expanding needs of professionals who conduct research; manage information resources, solve information, communication, and technology-related problems in businesses and other organizations; or who educate and/or train others in applications of information systems and communications" (XUNIVERSITY, 2018).

\section{Doctorate of Science - D.Sc.}

The degree that is offered in this regard is the Doctorate of Science (D.Sc.) degree. This is in contrast to the better known Doctorate of Philosophy (Ph.D.) degree. While the terminologies between the two degrees are seemingly different, the differences between the two degrees are best described as "subtle" with the primary difference lying in the research emphasis. Even the definition of the two degrees does not reveal a clear cut difference between the two degrees. The Brainy Encyclopeida defines Sc.D. or D.Sc. as "Abbreviation of the Latin Scientific Doctor. It is an academic degree on par with the wider known Ph.D. The D.Sc. is awarded predominantly in engineering sciences, whereas classical sciences seem to prefer the Ph.D." (NationMaster, 2004). The same web site defines Ph.D. as "an abbreviation of the Latin Philosophical Doctor .... Was originally a degree granted to a learned individual who had achieved the award and who had demonstrated a long and productive career in the field of philosophy" (NationMaster, 2004). Plus, the US Department of Education and the National Science Foundation recognize both research doctorates (NationMaster, 2004).

\section{A Research Doctorate Program}

The D.Sc. in Information Systems and Communications is a research degree appropriate for professionals with decision-making and problem-solving responsibilities related to information systems, communications, and technology, including

- Chief information officers, chief knowledge officers, network administrators, in-house consultants, training specialists and other managers of information technology resources in corporate and professional organizations.

- Educators and academic administrators in two-year, four-year, and graduate institutions, as well as information officers and managers in educational institutions.

- Professionals with a master's degree whose qualifications will be enhanced by such a doctoral degree, including those in fields such as accounting, finance, MIS, management, marketing, health care administration, telecommunications, and corporate communications.

The Structure of the Program

The program at XUniversity is designed so that students enrolled in it can complete it within six semesters (or three years). This kind of design is not much different from other doctoral programs. Doctoral programs, in general, list the 
degree requirements and suggest a sequence for completion. What distinguishes this program from other programs is the structure and support mechanism this is inherent to the program design. The structural enforcement mechanisms include a "lock step" cohort approach in which all students admitted at the same time take the same courses together in the same sequence.

Initially, an administrative member of the doctoral staff registers the students for the courses the students take each semester. The students do not have a choice among courses nor do they have options in the number of courses. The students must take three specific courses each semester in order to proceed to the next semester. In order to assure that the students take what is required, a doctoral program administrative staff member registers the students. This reduces the possibility of errors. Furthermore, this it facilitates the progression of students from one semester to the next, thus creating an enforcement mechanism for the specified course sequence.

Second, the course content is the same for all the students enrolled in the program. This includes the same textbooks, instructors, materials, assignments, and rigor. This policy helps to eliminate the disparity in course content and results in consistent knowledge base for each student in the cohort.

\section{Program Goals}

1- Develop and apply skills in a range of investigative methods, including qualitative methods grounded in economic, social and ethnographic disciplines, and quantitative methods grounded in statistical and social scientific disciplines.

2- Conduct research and design innovative, effective solutions to information management and information resource problems.

3- Stimulate field-based information management initiatives that link information, communications, technology, and systems within organizations.

4- Track new information technology and assist in incorporating it into an organization's strategy, planning, and practice.

\section{The Residency Weeks and Weekends}

The doctoral program at this university is conducted during the mandatory scheduled residency period. Each of the six terms has a scheduled residency of seven days (late August for the fall term and early January for the spring term) and three residency weekends each term held at 5-week intervals. The students enrolled in the program stay at a nearby hotel with reservations and accompanying logistics taken care of by the XUNIVERSITY staff. The hotel cost, food, and related expenses were integrated into the yearly tuition cost.

The residencies are tightly scheduled with formal classes and one-on-one faculty student meetings. The schedule runs from 8:00 AM to 9:00 PM with breaks every hour and a half, and time for lunch and dinner. Both class time and break time allow for both formal and informal discussion between faculty and students. Having a dedicated scheduled time for this program helps the students clarify issues regarding the course work and research in the following ways:

1- It helps with student-to-student communications. The students are there all day long and have the time to communicate with others regarding their course work.

2- It helps communicating with faculty also. Faculty members in the program attend the residency week/weekend also.

3- It may work as a channel to communicate with the administration in this program. The administrators of the program attend the residency week/weekend.

\section{The Cohort Enrollment Approach}

The cohort approach takes a different direction. In this approach, students start the program as one group (cohort), then take courses at the same time and move to complete the program together. Entering a program with a particular group of students, and taking courses with the same students, helps to reduce the feeling of isolation. It helps the students to get to know each other and share experiences among each other. But moreover, the content of the doctoral program at XUNIVERSITY include additional activities that help breaking isolation among the students themselves and also among the students and faculty alike.

1- Study and Discussion: This is an early day informal session that may be held over breakfast, thus is nicknamed the "breakfast club". 
2- Community Dinner: This is a meeting/dinner that is sponsored by the program. The dinner is held at the beginning of the semester and is attended by the students from the different cohorts, the faculty, and administrators of the programs.

3- Debriefings: These are sessions that are held at the end of the day. The debriefing meetings take place to discuss issues brought up during the day.

\section{The Field Project/Dissertation}

The field research project in this program is similar to doing a dissertation in other doctoral programs. Applied research is the focus of each field project. A field research project is developed through the following process:

1- A proposal for the field project must be submitted at the end of the second year and must be defended in front of a selected committee.

2- Following the approval of the proposal, work begins for data collection.

3- The field project must address a problem related to work and the attempts of this field project must be directed toward solving the proposed problem.

4- The student selects a committee that has at least three members. Also, the students are required to include one student from their cohort for reading and feedback.

5- The student is encouraged to select at least one member from the industry for which the project is written to ensure the practicality of the project.

In support of the field research project are three required seminars. Each seminar is focused on the student field project research. The first seminar is held the second semester of the second year. Its focus is the proposal. The second seminar is held in the third year, first semester, and it focuses on methodology and data analysis. The final seminar is held in the third year, second semester, and it focuses on writing and quality assurance. In each seminar, all the students go through a process of public presentation, defense, and review. The results of such peer evaluation and criticism is a better designed, developed, and written research project. The format and structure of this program has worked very well over the years.

\section{METHODOLOGY}

\section{Data Collection}

In order to collect the data, a survey was sent to the alumni of the program via QuestionPro.com. An open-ended survey was sent to 263 alumni of the Doctor of Science degree program at XUniversity in spring of 2018 and respondents were provided with a two-week period to take the survey. Forty-nine graduates originally answered the survey. A reminder was sent after a week to the same list of alumni. Fifty-six participants completed the survey, which is $21 \%$. The survey consisted of 13 items. Of those 13 items, six were open-ended questions specific to the program. The items on the survey, as mapped to research questions, were about the strengths, weaknesses, opportunities, and threats of the program along with effectiveness. To capture effectiveness, there was another openended item that asked if the program helped them further their goals. In essence, we had our graduates complete a S.W.O.T. analysis of the program. There were items to capture demographic information about the sample. These included their current positions, employer, and year of graduation. A description of their current employment status is provided below (table 1):

Table 1. Employment status of respondents

\begin{tabular}{|l|l|}
\hline Categories & Percentage of Total Participants \\
\hline Academia & $30 \%$ \\
\hline Corporate America & $36 \%$ \\
\hline Retired & $5 \%$ \\
\hline U.S. Government & $9 \%$ \\
\hline $\begin{array}{l}\text { N/A (Didn't answer because they believed they would } \\
\text { be recognized) }\end{array}$ & $20 \%$ \\
\hline
\end{tabular}




\section{Data Analysis}

The research team consisted of three faculty members who are associated with the program. The qualitative data from the survey was thematically analyzed and put into categories. The researchers took grounded theory approach (Glaser \& Strauss, 1967; Strauss and Corbin, 1990) and performed inductive coding. The data was coded and analyzed for themes in independent fashion and later collaboratively. Researchers worked independently to come up with themes and later collaborated to refine these themes for a consensus on labelling these categories.

The team's varied experience with the program required every individual to code the data on his or her own. The independent coding experience allowed an individual perspective to emerge. The first team member is the current program director and is associated with the program for three years. The second researcher has been teaching in this program for 8 years. The third researcher is one of the founders of the program and has been teaching in it since its inception. This member has been the program director for multiple years and teaches regularly in the program. The results of the analysis are presented in the next section. The information presented is to answer the research questions.

\section{Findings}

The first research question is about the strengths, weaknesses, opportunities, and threats for this program. The data presents following themes for these categories (see table 2).

Table 2. SWOT Analysis of DSc Program

\begin{tabular}{|c|c|}
\hline Strengths of the Program & Weaknesses of the Program \\
\hline $\begin{array}{ll}\text { - } & \text { Cohort format } \\
\text { - } & \text { Faculty support } \\
\text { - } & \text { Structure } \\
\text { - } & \text { Flexibility in pursuing ideas }\end{array}$ & $\begin{array}{l}\text { - } \quad \text { Less stringent admission standards } \\
\text { - } \quad \text { Inconsistency in syllabi } \\
\text { - } \quad \text { Few openings for teaching experience }\end{array}$ \\
\hline Potential Opportunities & Potential Threats \\
\hline $\begin{array}{l}\text { - } \text { Partner with industry on projects } \\
\text { - } \quad \text { Alumni engagement } \\
\text { - } \quad \text { Expand to specialty tracks }\end{array}$ & $\begin{array}{ll}\text { - } & \text { Cost of the program } \\
\text { - } & \text { Admission requirements } \\
\text { - } & \text { Title of the program }\end{array}$ \\
\hline
\end{tabular}

\section{Strengths of the Program}

The strengths identified by our respondents falls under four categories:

Cohort format: One of the major strengths of the program, as identified in the data, is the student experience as being part of a cohort. The cohort was an important part of getting everyone through the program. The cohort created a strong community feeling. The cohort was very helpful once everyone got to know each other. The participants felt that cohorts' members were supportive and students learned from each other. The structure of the cohort style was well thought through, and it accommodated working professionals especially well.

Faculty support: The second strength of the program, as identified by our respondents, was the faculty support. Several alumni mentioned that faculty are very supportive. The faculty, overall, is impressive and a true asset to the program. The faculty knowledge, experience, and patience exposed the students to new ways of thinking. Many respondents found faculty mentoring them all the way through the program and they hold valuable relationships after graduation. Close mentoring for students receiving doctoral level education is required for overall success of these candidates. As observed by one of the respondents:

At the time, faculty knowledge, experience, and patience to expose us to a new way of thinking, beyond our business background. The faculty made the program successful through its competency, and social commitment in building the relationships in the cohort concept.

Structure: The respondents found the structured 3-year schedule of the program very helpful. The structure is created with a working individual in mind and is designed for student success. Our alumni feel that the schedule contained built-in milestones and the progression of working through the dissertation was well paced and made the process much easier. The fact that students are oriented to thinking about their research topics on day one of the program followed 
by getting an advisor to work closely with in beginning of year two allows them conceptualize, mold, and solidify their research topics early on.

Flexibility in pursuing ideas: The last strength identified was being able to take an idea, develop it through an understanding of the literature, studying with different methodologies so that students are comfortable with the one that applies to their research. Layering the coursework over the dissertation allows for a better and shorter process in the program. Students can choose a dissertation topic that will help them in their career endeavors. One of the frustrating things in traditional doctoral programs is that students are encouraged to "fit-in" in an existing research agenda of the faculty. This program allows students to bring their own research problems and address it to the best of their abilities. The depth and variety of dissertation topics that have been produced in this program speaks to the diversity of ideas that are generated here.

\section{Weaknesses of the Program}

In response to our question about identifying weaknesses of the program, the data analysis suggests three emergent themes:

Less stringent admission standards: The biggest weakness expressed by the alumni was that not all students were held to the same standards while being admitted in the program. Respondents believe that there should be ways to weed out the weak students from the program. Some alumni believed that the admission criteria should be raised and the screening process needs to be more thorough.

Inconsistency in syllabi: The second weakness was that alumni felt that the syllabi should be more reflective of what is actually taught in the course. The syllabus document and the title of the course created expectations for students that were, in some cases, not completely fulfilled. They expected more depth in content and a focused approach in certain courses rather than the breadth or variety of concepts that was offered to them. Faculty were teaching the material related to the course description but were wandering in many directions in some cases.

Few openings for teaching experience: The last identified theme in weakness was that the program offers few teaching experiences to its current doctoral students. The alumni mentioned that several of them went into higher education teaching, and it would have been helpful to them if they had some exposure during the program to teaching in classrooms. They believe there should be an opportunity to get teaching experience while going through the program and that teaching should be included as a required part of the program.

\section{Potential Opportunities}

Based on our data, four themes were identified in the potential opportunities category of the survey. These themes are: Partner with industry on projects: Respondents believe that it would helpful for students if the program could collaborate with industry on research projects. Joining forces with industry would provide exposure to students in understanding current issues in businesses, and conducting research in conjunction with these companies would provide good insights into technical solutions being adopted and implemented. Students would get an opportunity to understand real organizational issues that could be addressed in a meaningful manner.

Alumni engagement: The second opportunity discussed was for alumni support and engagement. Our respondents suggested that the program could leverage alumni for co-instruction and guest speaking purposes thus highlighting their skills and accomplishments to current students. There are opportunities for outreach and incorporation of people and ideas into the curriculum and perhaps providing research grants opportunities as well. More post-graduation interaction, potential to work with doctoral candidates, master students, and undergraduates of XUNIVERSITY (as mentors or experts) would also be fulfilling to both sides. Inviting our graduates to be speakers, part of an advisory board, or research collaborators are all ways to enhance engagement after graduation.

Expand to specialty tracks: The last suggestion was to expand the program into specialty tracks, such as cyber security, forensics, and data analytics for those who want to focus on the more technical side of the degree. The data suggests that students would like an opportunity to be more specialized in a particular field and get specific content delivery in those areas of choice. 


\section{Potential Threats}

There are three themes in the threats section. These are:

Cost of the program: The most concerning threat expressed by the alumni was the high cost of the program. If the program is only viewed as a revenue generator, then it will fail. Costs continue to rise, but the alumni feel as though it is getting more out of reach for people who have no corporate sponsorship or opportunity for scholarship.

Admission requirements: The second threat expressed by the alumni was viewing every potential student the same. They would like to see stricter admission standards. If a student is underserving or sub-par, that student needs to be removed from the program. There is no need to push people through the program as it lowers the creditability of the degree for those who work hard to earn it.

Title of the program: The last threat mentioned was the name of the degree. The alumni expressed that perhaps a Ph.D. would be better than the D.Sc. Many employers give more weight to the Ph.D. degree, in their opinion. In addition, $\mathrm{PhD}$ as a degree is more recognized in industry as well as academia.

An effective doctoral program should be a positive empowering experience for its students. A doctoral program should help students accomplish their goals and objectives to be in such a program. For research question 2 , respondents were asked how was their overall experience in this program and if this program helped them further their career goals.

In response to "How would you describe your overall experience of the Doctor of Science program here at XUNIVERSITY?" the alumni expressed their experience as Excellent, Positive/Very Positive, Great Experience, or Good. Our respondents suggested a powerful, life changing and positive experience in the program. Two of the alumni mentioned that the XUNIVERSITY doctoral program changed their lives. As observed by a respondent:

Excellent! I highly recommend the program when appropriate and have used the work that I did in the program in my job including using my research project when talking with policy makers and regulators such as the Federal Communications Commission.

Their worldview and perspective of everything around them changed as a result of the program. Alumni mentioned that the program provided a diversified environment for students. Another respondent noted:

It is one of the most beneficial experiences I have ever had! It was hard at the beginning yes; specifically this program depends a lot on the research in each course in addition to working on your dissertation at the same time. This program strengthened my overall personality on different aspects especially confidence and research. I loved writing since I was a child, but you know writing is whole different thing compared to research.

In response to "How this program helped you further your careers goals?" the respondents found the program helped them accomplish their goals and objectives. The respondents moved towards their goals in an incremental manner and found new opportunities that they had not envisioned coming to them. As noted by a respondent:

Yes! - Improved the quality of my consulting work using evidence-based research methods and QA/QT analyses. I was able to obtain positions on editorial boards of academic and professional journals.

This program also helped many alumni move into academia from their current industry positions. As noted by a respondent:

Absolutely. It got me my first teaching job in higher education, and I now serve as the department chair.

Some respondents felt that overall benefit to them was not as quick as they would have liked. Being in a nonacademic job, it can be difficult to see immediate benefits of a terminal degree in the form of promotion or money. Respondents also agree that benefits accrue over a period and add gradually to make changes in their lives. As noted by a participant,

Yes, this program helped me with my goals. Everything in life is a step-by-step process. Therefore, in time I see myself moving to the pinnacle of my career. 
Overall, for research question 2, the perception of effectiveness of this program in our alumni is positive. They enjoyed the process of getting their degree and their expectations have been met, in some cases exceeded, after the degree was earned.

The next section presents a discussion on findings for our research questions. Implications are drawn and future research directions are provided.

\section{DISCUSSIONS AND CONCLUSION}

A high quality doctoral program involves a range of educational experiences that extend beyond coursework. Coursework can provide critical content and skills for leadership roles, but coursework alone may not be sufficient to motivate and retain doctoral students or provide them with necessary experiences associated with future job responsibilities, or socialize them to their new leadership positions (Noonan and Ballinger, 2007). Our data from alumni over 19 years suggests strengths, weaknesses, opportunities, and threats that provide interesting insights to the way this program has worked over the years and speaks to unique potential it holds in terms of expanding its horizons for future seekers of knowledge.

Our data suggests that there are four dominant strengths of the program: Cohort format, faculty support, structure, and flexibility in pursuing ideas. There are several benefits of having a cohort-based structure in a program, especially at a doctoral level. This finding is not surprising given the mentoring benefits of a cohort-based class where students get an opportunity to be mentored by faculty and peers. Faculty support for students is a huge advantage to them given their proximity to their advisors and ability to get into the survival mode during the program.

The culture of traditional $\mathrm{PhD}$ programs can make students snap. One of the main reasons why this frustration occurs is lack of commitment and clear communication from faculty members advising these students (Patterson, 2016). Professors do not invest time and effort in mentoring their students. It is effective to have mentoring early on during the program, and students should have access to multiple mentors in the program.

Mentoring from faculty benefits students tremendously. Some of these advantages include better research skills and productivity, more publications, student retention, and degree completion (Kram, 1985; Maher, Ford, \& Thompson, 2004). Students coming out of a program where they establish a bond with their faculty advisors are more productive in their work (Blank, 1988).

There are benefits of more seasoned doctoral students mentoring newer doctoral students. Peer-mentoring relationships provide a safe environment for giving and receiving feedback (Bonilla et al., 1994). Students are not worried about being evaluated or judged and feel free to vent their feelings. Similarly, Dorn, Papalewis, and Brown (1995) found that peer mentoring helped keep students moving towards degree completion.

Students have flexibility in choosing their research topics. The DSc program at XUNIVERSITY is more andragogical in nature and approach, as it is applicable in multiple contexts. The andragogical approach has changed the teaching philosophy of educators around the world. Given the current educational needs, the pedagogical approach has become less effective in teaching adult learners. Adult learners need more than passive transfer of knowledge from one person. Instead, they need to be involved actively in the learning process to construct their own knowledge, to make sense of the learning, and to apply what is learned (Chan, 2010). The DSc program attracts more experienced adult learners who have specific goals and outcomes mind when they choose this program. According to Zmeyoy (1998), andragogical principles are essential and widely needed in adult education. In the context of this program, it is a useful approach to teaching as these students have good amount of social experience, are aware of purpose of the degree and applicability of their knowledge and skills, have a good background in selected field and have short-term educational goals. This approach has worked well for the success of the program.

Weaknesses as identified in the data are: less stringent admission standards, inconsistency in syllabi, and few openings for teaching experience. Contrary to the perception of alumni, the criteria for admission is actually strict. There are several steps of admission process and at least two levels of interviews are conducted before a candidate is admitted into the program. Applicants write an essay discussing their motivation for the program and submit a writing sample for review of DSc faculty. An applicant is screened by the program director and then gets interviewed by a panel of faculty who teach in the program. The main qualities that are assessed in a potential candidate are his/her ability to 
write and reason, make inferences, and a passion for reading. Many of these candidates are out of school for several years, and these realities are factored in during the admission process.

The inconsistency in syllabi part refers to professors teaching things beyond the syllabus document. This can cause misalignment in expectations from students, and this is something that can be easily addressed in a faculty meeting by establishing common expectations of delivering what's mentioned in the syllabus document. The last weakness that was identified by the participants was lack of opportunities to teach during the program. This speaks to the limitations of school that is tied to collective bargaining agreement for full-time as well part-time faculty. Given the constraints of being able to fulfill all obligations of both these contracts, there are few courses left for doctoral students to teach. Also, their non-local presence does not help with staffing these courses.

The opportunities identified in this study are three-fold: partner with industry on projects, alumni engagement, and expand to specialty tracks. These are good opportunities to look into in the future. Collaboration with industry partners in some form of action research or some ongoing project provides benefits to students in terms of better understanding of complex problems out there in the business world and ways to address these problems. For industry partners, it is an opportunity to learn from rich body of knowledge to an area of concern and being able to apply some of these principles in real settings. Alumni of this program are committed to continued success of the program and are willing to give back in many ways. This unique talent pool could be utilized in multiple ways to strengthen the program further. They can participate in ongoing research, come back to classroom for guest lectures, participate in committees in their areas of expertise, be on advisory board, or help in recruitment for future cohorts. All these opportunities seem to have potential and could be utilized in the future.

The threats identified by the data are: cost of the program, admission requirements, and title of the program. One of the major concerns for the program was the increasing cost of the program. There has been an increment of about $100 \%$ in last ten years of the program. Even though this is a value-driven program and the return on investment is relatively high on successful completion, it is a heavy upfront investment on student's behalf. Our data also suggest that there is a preference for PhD title over DSc, and students tend to have to explain the meaning of this degree to their peers. The applied nature of this program makes it relatively high on the relevance scale in this whole debate on "rigor vs relevance" in academic research. The program is an avenue for working individuals who bring more experience to the program and tend to approach problems from a realistic market-driven perspective for their research. The real life problems being addressed in research agendas make a significant contribution to how things can be done in a more pragmatic and "hands-on" way rather than being limited to adding to theoretical body of knowledge in the field.

The perceived effectiveness of the program for our alumni, in terms of overall experience and in meeting goals of individuals, is definitely high. This program is not a traditional doctoral program where students are primarily trained to publish in academic journals and teach in higher education environment. This program is a perfect example of creating a balance between rigor and relevance and making academic knowledge usable to practitioners to solve actual problems.

The unique model of the program is acknowledged for its innovative approach to inform the practitioner world about research methods and body of knowledge in the field of information systems. Gill and Bhattacharya (2009) in an article in a leading information systems journal, MISQ, applauded the XUNIVERSITY DSc model where research and practice comes together to solve real problems. The authors recommended the DSc model as a "hybrid academicpractitioner doctoral program" that should be followed by other institutions that strive to make its research and knowledge generated more usable and relevant to industries at large. The working professionals, who graduate with a doctorate from this program, become a channel to transfer academic knowledge to practice and build symbiotic relationships between communities to generate resources for information systems programs (Gill and Bhattacharya, 2009).

There several implications of this study. First, this study provides a successful model, of convergence of IS and communications, for doctoral education. Doctoral programs across the country could benefit from this model of delivering quality education with a very high graduation rate. Second, it solidifies an example of how andragogical approaches are much better suited and results oriented for a program at this level than pedagogical approaches of knowledge transfer. Third, opportunities identified in this study emphasize the growing role of different modalities in delivering educational needs of tomorrow. Future research directions include a comparative study of student 
experience in a traditional versus a hybrid model such as DSc program. A comparison with fully online doctoral programs would inform us about the effectiveness of various modalities in delivering education.

This study presents a SWOT analysis of a doctoral program at XUniversity. A survey was administered about the strengths, weaknesses, opportunities, and threats of an existing doctoral program. A thematic analysis of the data presents insights into how the program benefits from its structure, format, and dedicated faculty. It also highlights areas that need improvement and potential opportunities that can be explored to add further value in this program. Implications are drawn and conclusions listed.

\section{REFERENCES}

Blank, M. A. (1988). Mentoring and the process of becoming a teacher. Unpublished doctoral dissertation, University of Tennessee, Knoxville.

Bonilla, J., Pickron, C., \& Tatum, T. (1994). Peer mentoring among graduate students of color: Expanding the mentoring relationship. New Directions for Teaching and Learning, 57, 101-113.

Chan, S. (2010). Applications of andragogy in multi-disciplined teaching and learning. Journal of Adult Education, $39(2), 25-35$.

Dorn, S. M., Papalewis, R., \& Brown, R. (1995). Educators earning their doctorates: Doctoral student perceptions regarding cohesiveness and persistence. Education, 116(2), 306-314.

Gill, G. \& Bhattacharya, A. (June 2009). Whom are we informing? Issues and recommendations for MIS Research from an informing sciences perspective. MIS Quarterly, 33(2), 217-235.

Glaser, B.G. \& Strauss, A. L. (1967). The discovery of grounded theory: Strategies for qualitative research. Chicago: Aldine Publishing Company.

Kram, K. E. (1985). Mentoring at work: Developmental relationships in organizational life. Glenville, IL: Scott, Foresman and Co.

Maher, M. S., Ford, M. E., \& Thompson, C. M. (2004). Degree progress of women doctoral students: Factors that constrain, facilitate, and differentiate. Review of Higher Education, 27(3), 385-408.

NationMaster (2004). Encyclopedia: Ph.D. http://www.nationamaster.com. Retrieved 11/15/2004.

Noonan. M. \& Ballinger, R. (2007). Peer and Faculty Mentoring in Doctoral Education: Definitions, Experiences, and Expectations. International Journal of Teaching and Learning in Higher Education, 19(3), 251-262.

O'Shaughnessy, Lynn. 12 reasons not to get a PhD, MoneyWatch, July 10, 2012 https://www.cbsnews.com/news/12-reasons-not-to-get-a-phd/

Patterson, T. Why do so many graduate students quit? The Atlantic, July 2016, https://www.theatlantic.com/education/archive/2016/07/why-do-so-many-graduate-students-quit/490094/

XUNIVERSITY (2018). Doctoral program at a glance. Retrieved April 6, 2018, from http://www.rmu.edu

Strauss, A. \& Corbin J. (1998). Basics of qualitative research techniques and procedures for developing grounded theory. London: Sage Publications.

Zmeyov, S. I. (1998). Andragogy: Origins, developments and trends. International Review Education, 44(1), 103108. 